\title{
Convergence of Reflex Pathways Excited by Distension and Mechanical Stimulation of the Mucosa onto the Same Myenteric Neurons of the Guinea Pig Small Intestine
}

\author{
T. K. Smith, ${ }^{1, a}$ J. C. Bornstein,, ${ }^{2, b}$ and J. B. Furness ${ }^{1, b}$ \\ Centre for Neuroscience, and 'Departments of Anatomy and Histology and of ${ }^{2}$ Physiology, Flinders University School of \\ Medicine, Bedford Park, South Australia 5042, Australia
}

The effects on morphologically and electrophysiologically characterized myenteric neurons of activation of intestinal reflex pathways were examined in vitro. Opened segments of guinea pig small intestine were pinned serosa down in an organ bath that had two balloons set into its base. A 5-10mm-wide strip of myenteric plexus between the balloons was exposed from the mucosal side, and neurons were impaled with microelectrodes. Reflex pathways were stimulated by inflation of the balloons to distend the intestinal wall, and by deforming the exposed mucosal villi with a brush. Impaled neurons were classified electrophysiologically as AH-neurons or S-neurons (Hirst et al., 1974) and were injected with biocytin to determine their shapes and projections. None of the $58 \mathrm{AH}-$ neurons responded to distension. In contrast, 63 of 131 S-neurons responded to distension with a burst of fast EPSPs; about one-third of the responding S-neurons received input from ascending reflex pathways, one-third received input from descending reflex pathways, and onethird received input from both ascending and descending pathways. Most neurons in this last group supplied extensive varicose branches to the tertiary plexus and were probably longitudinal muscle motor neurons. Neurons receiving input from only one pathway usually projected in the direction of that pathway; many of these were circular muscle motor neurons. Almost all neurons responding to distension were also excited by deforming the villi. Responses evoked by distension or deforming the mucosa declined when stimuli were repeated at intervals less than $10 \mathrm{sec}$. This was seen in ascending and descending pathways but was more prominent in the former. Deforming the mucosa evoked a normal response even when the response to repeated distensions had disappeared. It is concluded that distension and deforming the mucosa excite separate populations of sensory

Received July 8, 1991; revised Nov. 8, 1991; accepted Nov. 19, 1991.

This work was supported by a Program Grant from the National Health and Medical Research Council of Australia. We thank Ms. Di Trussell and Mrs. Janine Falconer-Edwards for expert technical assistance.

Correspondence should be addressed to Dr. J. C. Bornstein, Department of Physiology, University of Melbourne, Parkville, Victoria 3052, Australia.

a Present address: Division of Gastroenterology, Departments of Internal Medicine and Physiology, Health Sciences Center, University of Virginia, Charlottesville, VA 22908.

${ }^{b}$ Present address: Department of Physiology, University of Melbourne, Parkville, Victoria 3052, Australia.

Copyright @ 1992 Society for Neuroscience $0270-6474 / 92 / 121502-09 \$ 05.00 / 0$ neurons to activate reflex pathways that converge onto common motor neurons and probably onto common interneurons.

Distension of the intestine evokes a stereotyped reflex in which the circular muscle contracts on the oral side of the stimulus and relaxes on the anal side (Bayliss and Starling, 1899). Although this has been known since the turn of the century, information about the patterns of activity and physiological connections of the enteric neurons that mediate these reflexes is very limited. In the guinea pig small intestine, the neuronal circuitry responsible for reflexes activated by distension is largely contained within the myenteric plexus (Smith et al., 1990) and includes sensory neurons, interneurons, and both excitatory and inhibitory motor neurons (Furness and Costa, 1987).

The behavior of myenteric neurons during intestinal reflexes has been examined with intracellular electrodes in only two substantial studies. Hirst and his colleagues (Hirst and McKirdy, 1974; Hirst et al., 1975) examined the effects of distension of an intestinal segment on myenteric neurons at the end of the segment, $2-5 \mathrm{~cm}$ from the distension site. They found that distension of a segment of intestine lying oral to the point of recording evoked bursts of fast EPSPs in most neurons of the electrophysiologically defined class known as S-neurons (Hirst et al., 1975). The other major population of myenteric neurons, AH-neurons, did not respond to distension (Hirst and McKirdy, 1974; Hirst et al., 1975). In these experiments, no neurons lying on the oral side of the distended segment responded to the stimulus and it was concluded that distension excited descending (oral to anal) reflex pathways, but not ascending (anal to oral) pathways. More recently, Bornstein et al. (1991) studied the responses evoked in myenteric neurons by mechanically deforming the mucosal villi. They found that both ascending and descending reflex pathways were excited by this stimulus and that these pathways selectively excited S-neurons at distances greater than $4 \mathrm{~mm}$ from the stimulus. In this study, the morphology and projections of the electrophysiologically identified myenteric neurons were determined. However, this was not possible in the earlier studies of the responses of myenteric neurons to distension (Hirst and McKirdy, 1974; Hirst et al., 1975).

A major aim of the present study was to reexamine the responses of electrophysiologically defined myenteric neurons to distension and to correlate the responses seen with the mor- 


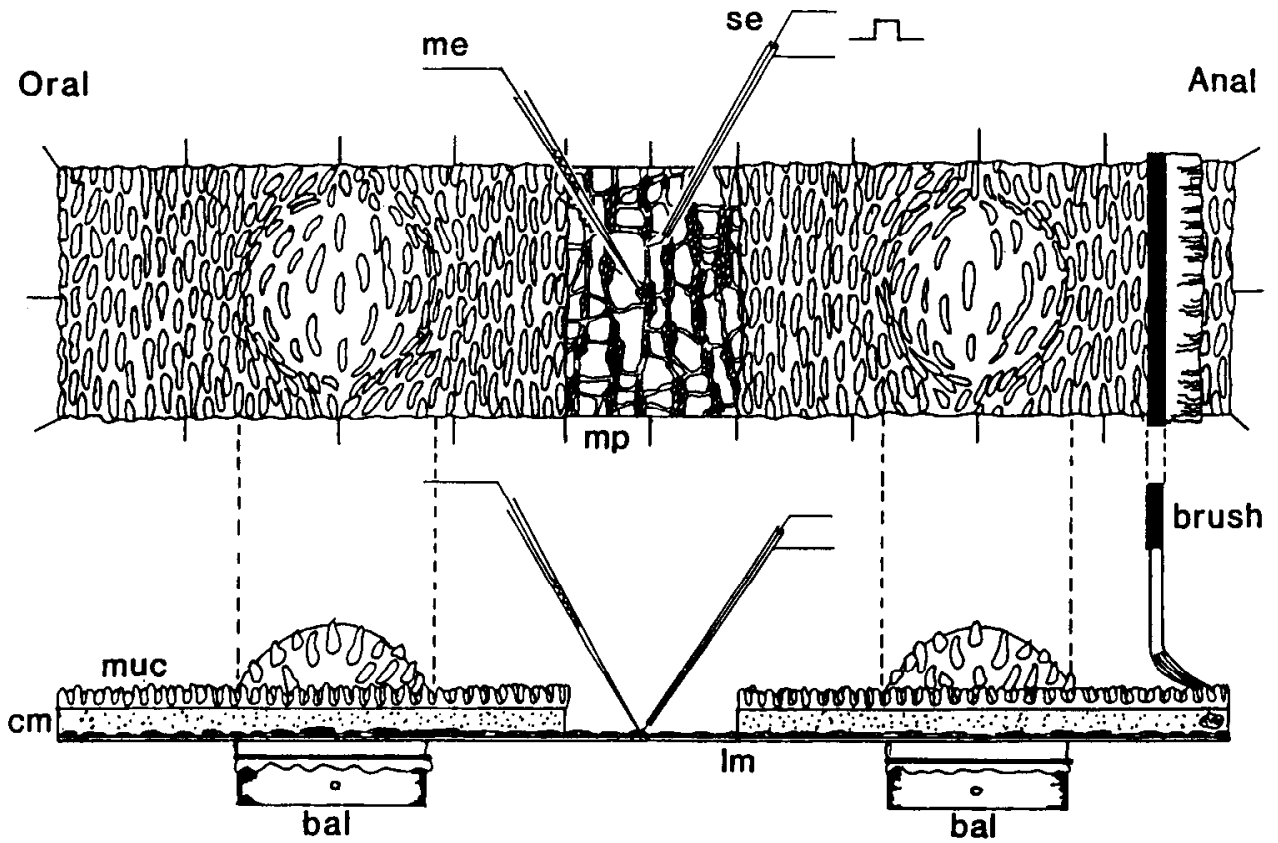

Figure 1. The preparation used in these experiments. The upper panel shows a plane view, and the lower, a cross-scctional view of a segment of guinea pig small intestine that had been opened along its mesenteric border and pinned flat, mucosa up, in an organ bath with two hemispherical balloons ( $b a l$ ) set into its base. A 5-10-mm-wide strip of myenteric plexus ( $\mathrm{mp}$ ) and longitudinal muscle $(l \mathrm{~m})$ was cleared between the two balloons, and recordings were made from neurons within this region using intracellular microelectrodes $(m e)$. Internodal strands were electrically stimulated in the cleared region using a focal stimulating electrode (se). Reflexes were evoked at either the oral or the anal end of the preparation by inflating a balloon to distend the intestine or by stroking the exposed mucosal villi with a brush. $\mathrm{cm}$, circular muscle; $m u c$, mucosa. phology and projections of the neurons from which recordings were made. A second aim was to examine whether neurons receiving input from one reflex pathway also received input from other reflex pathways.

\section{Materials and Methods}

Segments of guinea pig small intestine opened along their mesenteric borders and pinned in an organ bath with the serosa down (Fig. 1) were used in these experiments (Smith et al., 1990). Hemispherical balloons ( $6 \mathrm{~mm}$ diameter, separated by $30 \mathrm{~mm}$ ) were set into the base of the organ bath and could be inflated to stretch the section of intestine pinned over them. The mucosa, submucosa, and circular muscle were dissected away from a $5-10-\mathrm{mm}$-long region between the balloons to create an "island" of exposed myenteric plexus. A loose fold of uncleared intestine (up to $5 \mathrm{~mm}$ long) was left between each balloon and the area of cleared myenteric plexus to minimize movement at the recording site, but the intestinal regions over the balloons were more tautly pinned. The cleared region of myenteric plexus lay between $10 \mathrm{~mm}$ and $15 \mathrm{~mm}$ from the nearest edge of each of the distending balloons so that the impaled neurons were between 15 and $30 \mathrm{~mm}$ from the near edge of either balloon. Because it was not possible to determine exactly where the reflex evoked by a distension was initiated by the $6-\mathrm{mm}$-diameter balloons, the positions in relation to the balloons of individual impaled neurons were not determined precisely.

Throughout the dissection and recording period the preparation was bathed in a physiological saline solution (Bornstein et al., 1991), containing 1-3 $\mu \mathrm{M}$ nicardipine and $1 \mu \mathrm{M}$ hyoscine to minimize contractions of the intestinal muscle.

Intracellular recordings were made from neurons in the cleared region of myenteric plexus using microelectrodes filled with $4 \%$ biocytin in 2 $\mathrm{M} \mathrm{KCl}$ (buffered to $\mathrm{pH} 7.4$ with $0.05 \mathrm{M}$ Tris) (Bornstein et al., 1991). Neurons were characterized electrophysiologically as either S-neurons or AH-neurons according to the criteria first described by Hirst et al. (1974). Three different types of stimuli were used to examine the propcrtics of the impaled neurons. An etched tungsten electrode (tip diameter, $20 \mu \mathrm{m}$ ) was used to provide focal electrical stimuli to circumferentially directed internodal strands leaving the ganglia containing impaled neurons. Reflex responses were evoked by inflating the balloons set into the base of the organ bath to distend the intestine either oral or anal to impaled neurons (Smith et al., 1990). The distension volumes were always greater than $0.2 \mathrm{ml}$ and were chosen because $0.15 \mathrm{ml}$ injected into similar balloons evokes substantial reflex responses in the circular muscle (Smith et al., 1990; Yuan et al., 1991). If a neuron showed no response to a particular distension volume, the volume in- jected into the balloon was increased to at least $1 \mathrm{ml}$ before it was concluded that the neuron did not respond to distension. When trains of distensions were applied, the distension volumes were held constant within the train and comparisons between trains were only made when identical stimulating volumes were used in each train. If a neuron responded to distension, mechanical stimuli were applied to the mucosa either with a hand-held artist's brush or with a mechanically driven brush made from a cut duck feather (Smith and Furness, 1988; Bornstein et al., 1991).

In some cases, a longer preparation was used and three balloons were set into the base of the bath so that the effects of distension at different distances could be studied. In these cases, a loose fold of tissue was left between the two balloons that were on one side of the cleared region so that stretching the intestinal wall using one balloon did not stimulate the region around the other balloon.

After the electrophysiological behavior of an impaled neuron had been characterized, hyperpolarizing current $(0.4-1.0 \mathrm{nA})$ was passed through the recording electrode to facilitate the diffusion of biocytin into the neuron (Bornstein et al., 1991). The ganglion containing the impaled neuron was then drawn and the position of the recording electrode indicated. Subsequent impalements were made into other ganglia or into clearly distinguishable parts of the original ganglion, so that the impaled neuron could be uniquely identified after processing to reveal the biocytin. At the end of each experiment, the preparation was fixed and processed to reveal the neurons injected with biocytin as described elsewhere (Bornstein et al., 1991). The shapes and projections of these neurons were determined using phase-contrast optics and were drawn using a camera lucida.

\section{Results}

The effects of distension of the intestinal wall at one or more sites were examined in 189 electrophysiologically characterized myenteric neurons in 51 preparations. Fifty-eight of these neurons were characterized as $\mathrm{AH}$-neurons, because their action potentials were followed by slow afterhyperpolarizations (Hirst et al., 1974). Focal electrical stimulation of a circumferentially directed internodal strand evoked prominent fast EPSPs in the other 131 neurons, which were therefore classified as S-neurons (Hirst et al., 1974). Such stimuli did not evoke prominent fast EPSPs in the AH-neurons, although they usually evoked antidromic action potentials that propagated into the impaled cell bodies of these neurons. 


\section{A. Ascending}
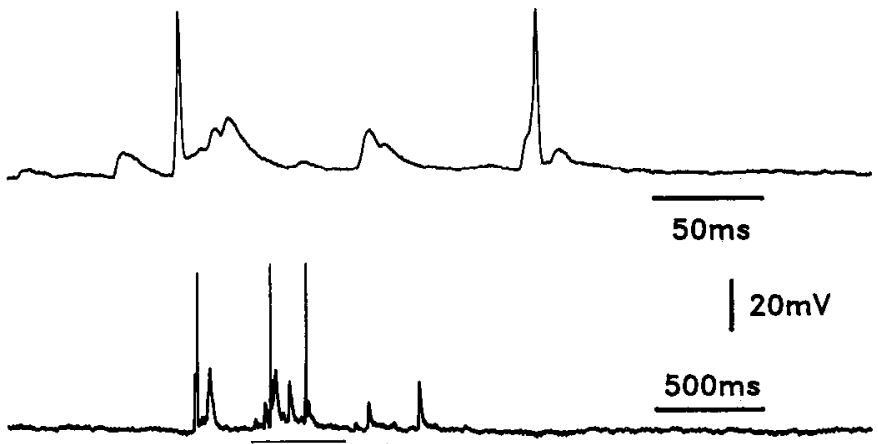

\section{B. Descending}
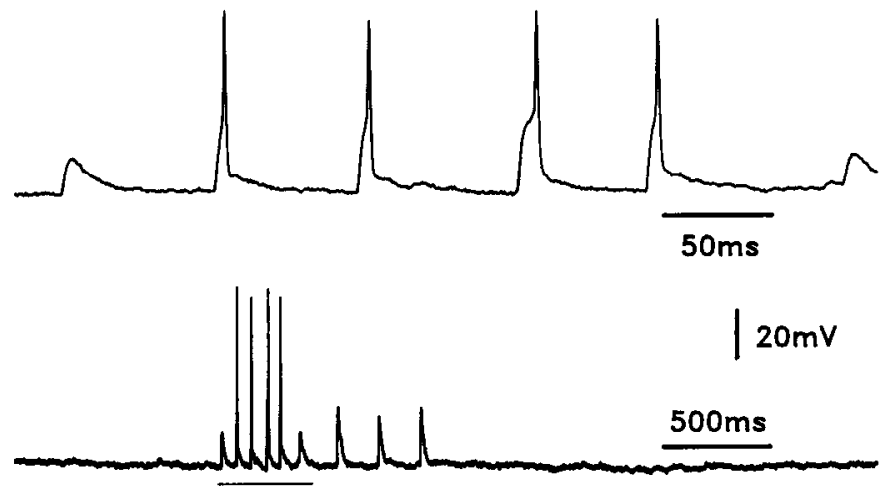

Figure 2. Examples of the responses recorded intracellularly from two S-neurons in response to distension. In $A$, a balloon was inflated by injection of $1 \mathrm{ml}$ of saline to distend a segment of intestine on the anal side of the impaled S-neuron so that the response was due to activation of an ascending reflex pathway. In $B$, the distending balloon was oral to the recording site, so that the response was due to activation of a descending pathway (distending volume, $0.5 \mathrm{ml}$ ). In both $A$ and $B$, the lower trace shows the time course of the distension, the middle trace shows the response of the neuron on the same time scale, and the upper trace shows a portion of this response (from the region indicated by the line under the middle trace) on an expanded time scale. The expanded trace shows that in each case the response consists of fast EPSPs that sometimes initiate action potentials.

\section{Reflexes evoked by distension}

Inflation of a balloon (distending volume, $0.1-0.3 \mathrm{ml}$ ) lying anal or oral to the recording site evoked bursts of fast EPSPs in many S-neurons (e.g., Fig. $2 A, B$ ). Thus, distension activates both ascending and descending reflex pathways that excite S-neurons in the myenteric plexus. Of $131 \mathrm{~S}$-neurons tested, 41 responded to inflation of an orally placed balloon and 40 responded to inflation of an anally placed balloon. The convergence of ascending and descending pathways was examined for $118 \mathrm{~S}-n e u-$ rons, and 18 responded to activation of both the ascending and descending pathways, 20 only responded to activation of the ascending reflex pathways, and 20 only responded to activation of the descending reflex pathway.
In contrast to the $\mathrm{S}$-neurons, no responses were recorded from any of the $58 \mathrm{AH}$-neurons studied in response to distensions applied either oral or anal to the recording site.

Although slow EPSPs in both AH- and S-neurons are a prominent response to electrical stimulation of internodal strands in the guinea pig small intestine (Johnson et al., 1980; Bornstein et al., 1984), distension was not found to evoke slow EPSPs in any of the neurons examined in the present study.

\section{Dynamic properties of distension-evoked reflexes}

The properties of the responses evoked by distension were analyzed in detail for 14 neurons that received input from ascending pathways and 12 neurons that received input from descending pathways. Latencies of the responses (i.e., the bursts of fast EPSPs) were measured from the beginning of each distension to the onset of the first EPSP and varied widely even within a single neuron. For example, the latency to the first fast EPSP in one neuron in the ascending pathway varied from 0.51 sec to $1.09 \mathrm{sec}$ in six trials, each separated by at least $2 \mathrm{~min}$. Similar variations were seen in other neurons in ascending pathways and in all neurons in descending pathways. The mean latencies also varied widely between neurons, with neurons in the ascending pathways having mean latencies ranging from $0.23 \mathrm{sec}$ to $1.18 \mathrm{sec}$ [overall mean, $0.70 \pm 0.28 \mathrm{sec}$ (SD), $n=$ 14] and neurons in the descending reflex pathways having mean latencies ranging from $0.30 \mathrm{sec}$ to $1.06 \mathrm{sec}$ (overall mean, 0.79 $\pm 0.22 \mathrm{sec}, n=12$ ). Thus, the latencies of the responses evoked by distension did not differ significantly between the ascending and descending pathways activated by distension.

The number of fast EPSPs evoked by a distension also varied between stimuli for individual neurons in both the ascending and descending pathways. For example, successive distensions separated by $>2 \mathrm{~min}$ evoked responses ranging from 17 to 40 fast EPSPs in the neuron in the ascending pathway cited in the previous paragraph. The mean numbers of fast EPSPs evoked in individual neurons in the ascending pathway ranged from 1 to 29.8 (mean, $10.0 \pm 9.5$ ) and in the descending pathway ranged from 3.0 to 35.7 (mean, $10.6 \pm 8.7$ ). Thus, the number of fast EPSPs evoked by distension did not appear to differ significantly between the ascending and descending pathways excited by distension.

However, the durations of the responses (measured from the first fast EPSP to the last fast EPSP in the response) observed in neurons in the ascending pathway were significantly shorter $(p<0.01)$ than the durations of the responses seen in the descending pathway. The mean durations of the responses in neurons in the ascending pathway (omitting four neurons that responded to distension with a single fast EPSP) ranged from 0.06 sec to $1.68 \mathrm{sec}$ (mean, $0.72 \pm 0.52 \mathrm{sec}, n=10$ ), but those in neurons in the descending pathway ranged from $0.30 \mathrm{sec}$ to 5.15 sec (mean, $1.96 \pm 1.43 \mathrm{sec}, n=12$ ). Despite the more prolonged responses seen in the descending pathways, the bursts of fast EPSPs evoked by inflation of the oral balloon did not consistently persist beyond the duration of that inflation.

The more prolonged responses seen in the descending pathway were reflected in a lower mean frequency of the fast EPSPs making up the responses. The mean frequencies in responses in the ascending pathways ranged from $8 \mathrm{~Hz}$ to $32 \mathrm{~Hz}$ (mcan, 20 $\pm 9 \mathrm{~Hz}$, excluding four neurons that responded with one fast EPSP only); those in the descending pathway ranged from $2 \mathrm{~Hz}$ 

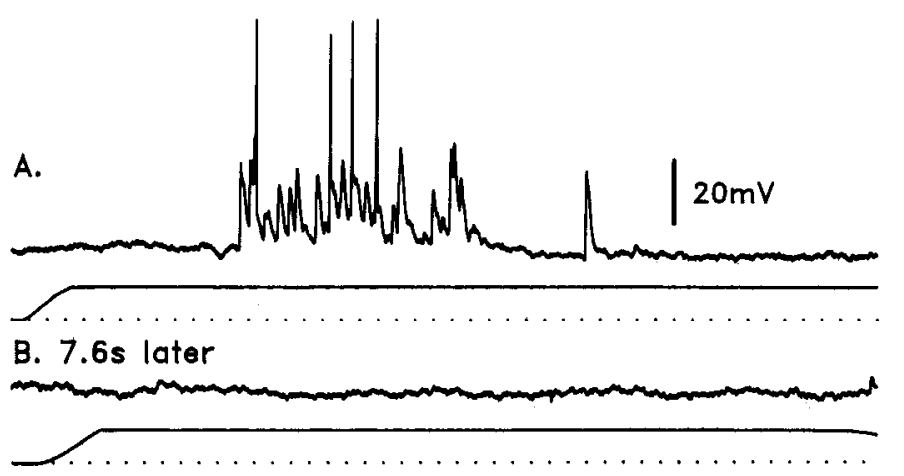

C. $8.5 \mathrm{~s}$ later
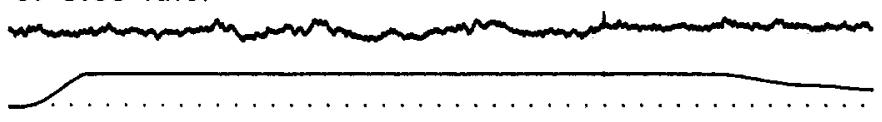

D. 5.9 s later

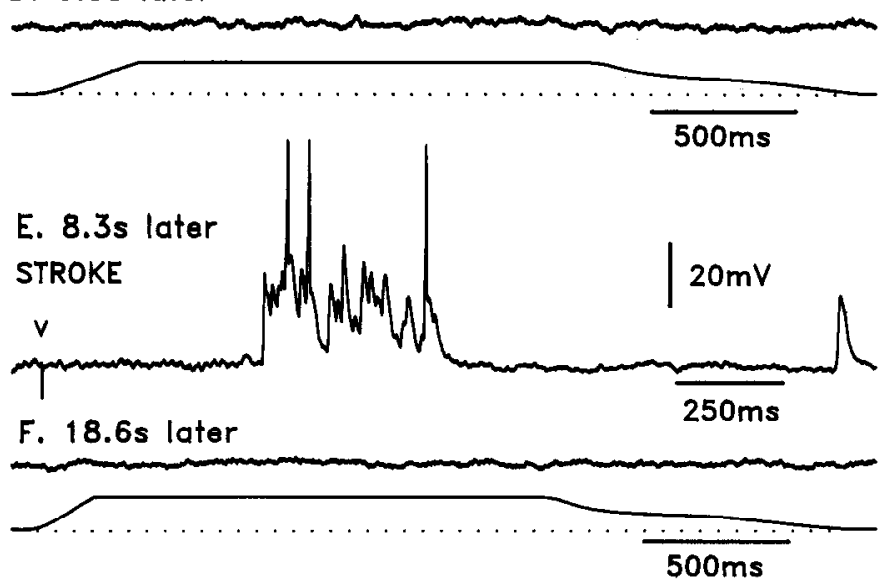

Figure 3. The responses evoked by several successive reflex stimuli applied on the anal side of a single S-neuron. The stimuli in $A-D$ and $F$ were distensions of equal volume $(1 \mathrm{ml}$ ) (shown in the lower trace of each of these records), while that in $E$ was distortion of the mucosal villi at the site of the distensions. The stimuli were initiated at intervals of $7.6 \mathrm{sec}(A-B), 8.5 \mathrm{sec}(B-C), 5.9 \mathrm{sec}(C-D), 8.3 \mathrm{sec}(D-E)$, and 18.6 $\sec (E-F)$. Despite the failure of later distensions in the sequence to evoke a response in the impaled neuron, mucosal distortion at the same site evoked a substantial response in this neuron.

to $14 \mathrm{~Hz}$ (mean, $5.6 \pm 3.6 \mathrm{~Hz}$ ). The frequencies within responses were often much higher than the mean frequencies, and fast EPSPs separated by intervals of $5 \mathrm{msec}$ (giving an instantaneous frequency of $200 \mathrm{~Hz}$ ) were commonly observed during responses evoked in either ascending or descending pathways.

Distensions often evoked fast EPSPs that were suprathreshold for the generation of action potentials in either pathway (Fig. 2 ). The frequencies of these action potentials were sometimes as high as $40 \mathrm{~Hz}$ in the ascending pathway and $17 \mathrm{~Hz}$ in the descending pathway. These frequencies presumably did not represent the maximal physiological firing frequencies of the neurons, as deforming the mucosa could evoke action potentials with frequencies up to $70 \mathrm{~Hz}$ in the same neurons (see below). In other cases, the fast EPSPs evoked were subthreshold. However, as hyperpolarizing current was often injected into neurons to stabilize the impalements (between 0.02 and $0.5 \mathrm{nA}$ was injected into about half the responding S-neurons to hold their apparent membrane potentials to ncar $60 \mathrm{mV}$ ), it was not possible to estimate realistically the number of neurons that received suprathreshold input from the reflex pathways.

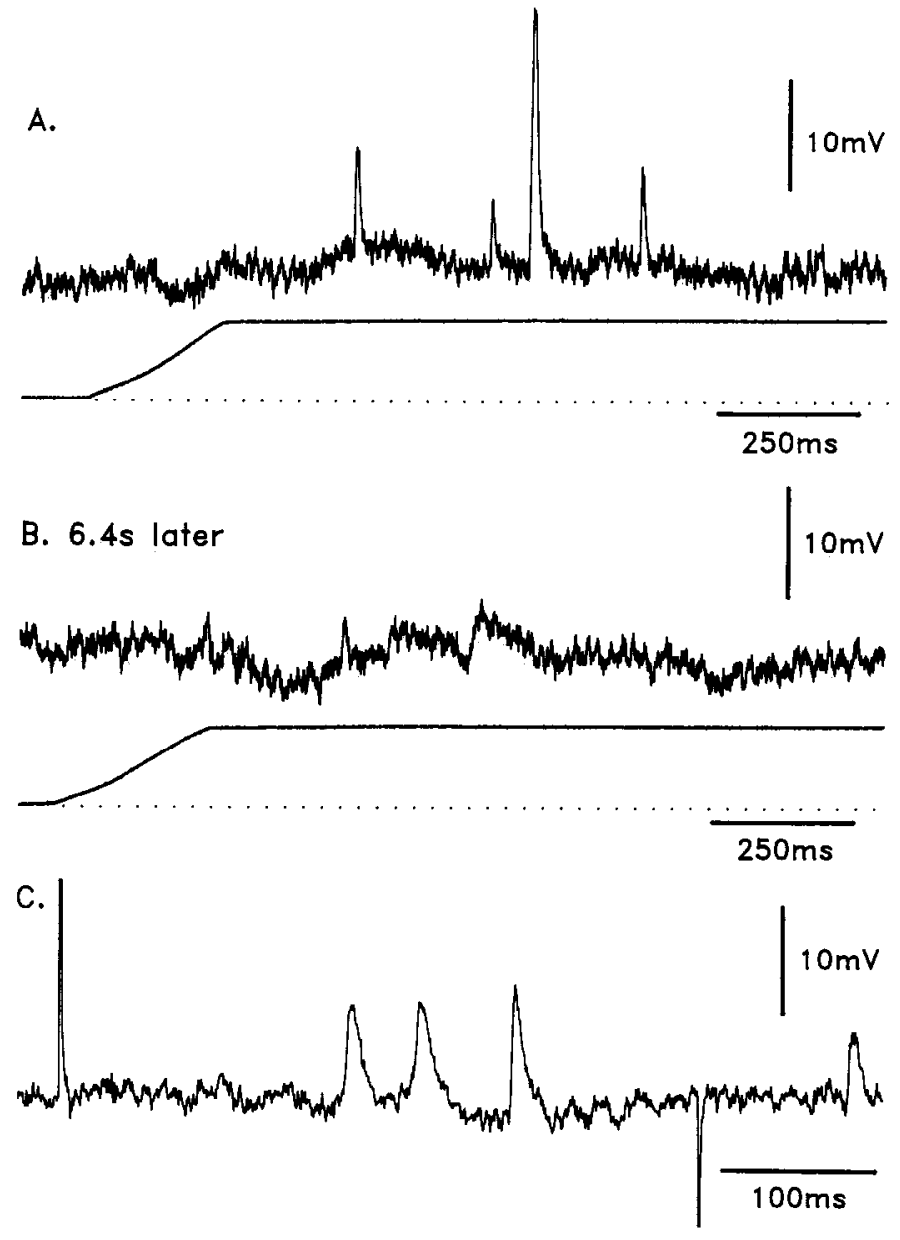

Figure 4. The responses evoked by three successive reflex stimuli applied oral to an impaled S-neuron. The stimuli in $A$ and $B$ were distensions (volume, $0.3 \mathrm{ml}$ ), while that in $C$ was distortion of the mucosal villi at the same site. The stimuli were initiated at intervals of $5.7 \mathrm{sec}$ $(A-B)$ and $8.2 \mathrm{sec}(B-C)$. The sharp upward deflection at the beginning of the trace in $C$ is an electrical artifact showing the point at which the mechanically driven brush used to stimulate the mucosa touched the tissue; the downward deflection shows the time at which the brush was removed.

\section{Depression of the reflex responses by prior stimulation}

The bursts of fast EPSPs evoked by distension rarely lasted until the distending balloon was deflated (e.g., Fig. 2). Even in the descending pathway, where responses lasting several seconds (up to $6 \mathrm{sec}$ ) during prolonged distensions were common, extending the duration of the distension showed that the response was not maintained throughout.

When distensions were repeated at intervals less than 1 every 2 min, the number of fast EPSPs evoked by the later stimuli was reduced (Figs. 3, 4). This effect was especially prominent for neurons responding to input from ascending pathways when the intervals between stimuli were less than $10 \mathrm{sec}$ (Fig. 3). For example, in one cell that received input from an ascending pathway, the number of fast EPSPs evoked by a distension fell from a mean of $21.2 \pm 4.0(n=5)$ for the first distension to $0.6 \pm$ $0.9(n=5)$ for a distension of identical size delivered 5-8 sec after the initial stimulus. Although it was less consistent, a similar decline was also seen in neurons responding to input from descending pathways (Fig. 4). 


\section{A. Oral distension}

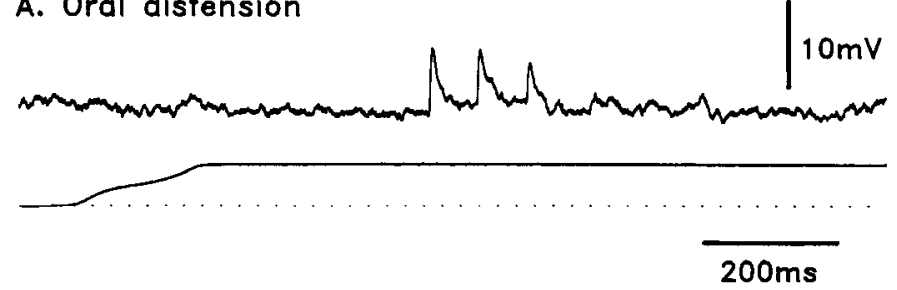

B. Anal distension

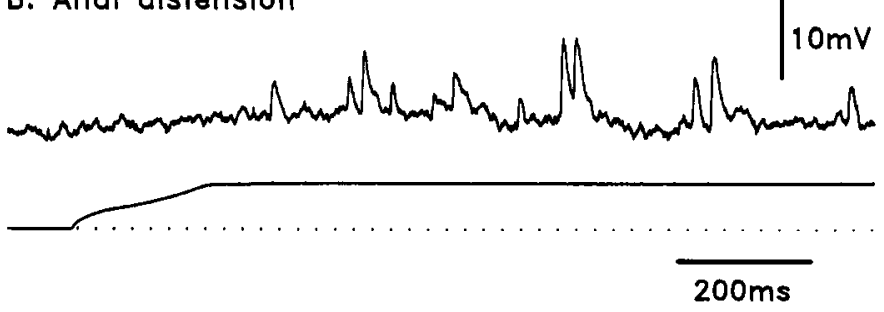

Figure 5. Convergence of ascending and descending reflex pathways excited by distension onto a single S-neuron. $A$, The response evoked by distension (volume, $1 \mathrm{ml}$ ) of the intestine oral to the neuron. $B$, The response evoked by distension (volume, $0.45 \mathrm{ml}$ ) of the intestine anal to the neuron. Fach stimulus evoked fast EPSPs in this S-neuron.

\section{Convergence of the ascending and descending reflex pathways}

A significant proportion of neurons that received input from one pathway also received input from the other (Fig. 5). Of 118 S-neurons that were tested for responses to distension of both an oral balloon and an anal balloon, 60 did not show any response, 20 responded to the oral distension, 20 responded to the anal distension, and 18 responded to both distensions. Thus, about a third of all neurons that responded to distension were in both the ascending and the descending pathways.

\section{Correlation of projections and direction of inputs}

As reported earlier (Bornstein et al., 1991), injection of biocytin into myenteric neurons can, after suitable processing, allow the processes of impaled neurons to be traced for up to $7 \mathrm{~mm}$ within the myenteric plexus. Of the $131 \mathrm{~S}$-neurons examined in this study, 72 were sufficiently well stained to allow their shapes and projections to be identified. Bornstein et al. (1991) found that $S$-neurons can be broadly divided into four groups on the basis of the directions their single processes took within the myenteric plexus. Neurons of one group had major processes that divided fairly close to their cell bodies and then supplied many varicose branches to the tertiary plexus. These neurons are probably motor neurons innervating the longitudinal muscle. Another group of neurons projects anally along the intestine; this group includes both descending interneurons and long inhibitory motor neurons innervating the circular muscle. A third group projects orally along the intestine and includes both ascending interneurons and long excitatory motor neurons. The fourth group of neurons projects circumferentially around the intestine and usually projects only a short distance either orally or anally. Many of this last group are probably motor neurons to the circular muscle, as their processes sometimes entered and became varicose within superficial strands of circular muscle adhering to the otherwise cleared preparation (Fig. 6).

Table 1 summarizes the projection patterns of the neurons whose responses to distension were characterized. Several consistent patterns can be discerned. For example, all but 2 of the
Table 1. Projection patterns of S-neurons whose responses to distension had been characterized

\begin{tabular}{lccccc}
$\begin{array}{l}\text { Response to } \\
\text { distension }\end{array}$ & Total & Tert & Oral & Anal & Circ \\
\hline Nonresponders & 40 & 2 & 7 & 22 & 9 \\
Desc & 7 & 1 & 0 & 4 & 2 \\
Asc & 13 & 2 & 9 & 1 & 1 \\
Both & 12 & 8 & 1 & 1 & 2 \\
Total for class & 72 & 13 & 17 & 28 & 14
\end{tabular}

The neurons were divided into four groups according to the effects of distension: nonresponders, those that received input from descending pathways only (Desc), those that reccived inputs from ascending pathways only (Asc), and those that received input from both pathways (Both). Four different projection patterns were identified: tertiary plexus neurons (Tert), orally projecting neurons (Oral), anally projecting neurons (Anal), and circumferentially projecting neurons (Circ). Most circumferentially projecting neurons appear to be motor neurons to the circular muscle.

13 tertiary plexus neurons that were identified responded to distension with a burst of fast EPSPs. Eight of these neurons responded to distension from both directions, indicating that the ascending and descending reflex pathways converge on this class of enteric motor neurons. Neurons that only received input from the ascending pathway typically projected either circumferentially or orally; only 1 of 13 projected anally. In contrast, none of the seven neurons that only received input from the descending reflex pathway projected orally. Although some neurons of all the different projection patterns did not respond to distension, significantly more neurons that projected anally failed to respond to distension than did respond ( $p \ll 0.001, \chi^{2}$ test). Most of these anally projecting nonresponding neurons (18 of 22) had the shape of Dogiel type I neurons, that is, many short lamellar processes and a single long process (Dogiel, 1899).

Several of the neurons that projected along the intestine (either orally or anally) branched after running 1-3 $\mathrm{mm}$ in the myenteric plexus. After branching, these processes often became varicose and ran circumferentially with circular muscle strands that had been left attached to the cleared myenteric plexus (Fig. 6). The varicose branches usually ended in expansion bulbs indicating points where the processes had been disrupted in the dissection (Erde et al., 1985) and presumably would have penetrated more deeply into the circular muscle. Other longitudinally projecting neurons ended in expansion bulbs within internodal strands, and some simply became too faint to detect $3-5 \mathrm{~mm}$ from the cell body. It seems likely that the neurons whose processes ramified in the circular muscle were motor neurons to this muscle layer, as were some of the other longitudinally projecting neurons.

The shapes and projections of $32 \mathrm{AH}$-ncurons were also determined. These matched those of this class of neurons described elsewhere (Bornstein et al., 1992). The AH-neurons all had large smooth cell bodies with several long processes that projected circumferentially to ramify extensively in both their ganglion of origin and in neighboring ganglia, a shape defined by Dogiel (1899) as type II.

\section{Convergence of distension and mucosal reflex pathways}

The possibility that deforming the mucosa could excite the same neurons as those that were excited by distension was examined, and the results are shown in Table 2. Mucosal reflexes were activated by distorting the villi over the balloon sites. Most 


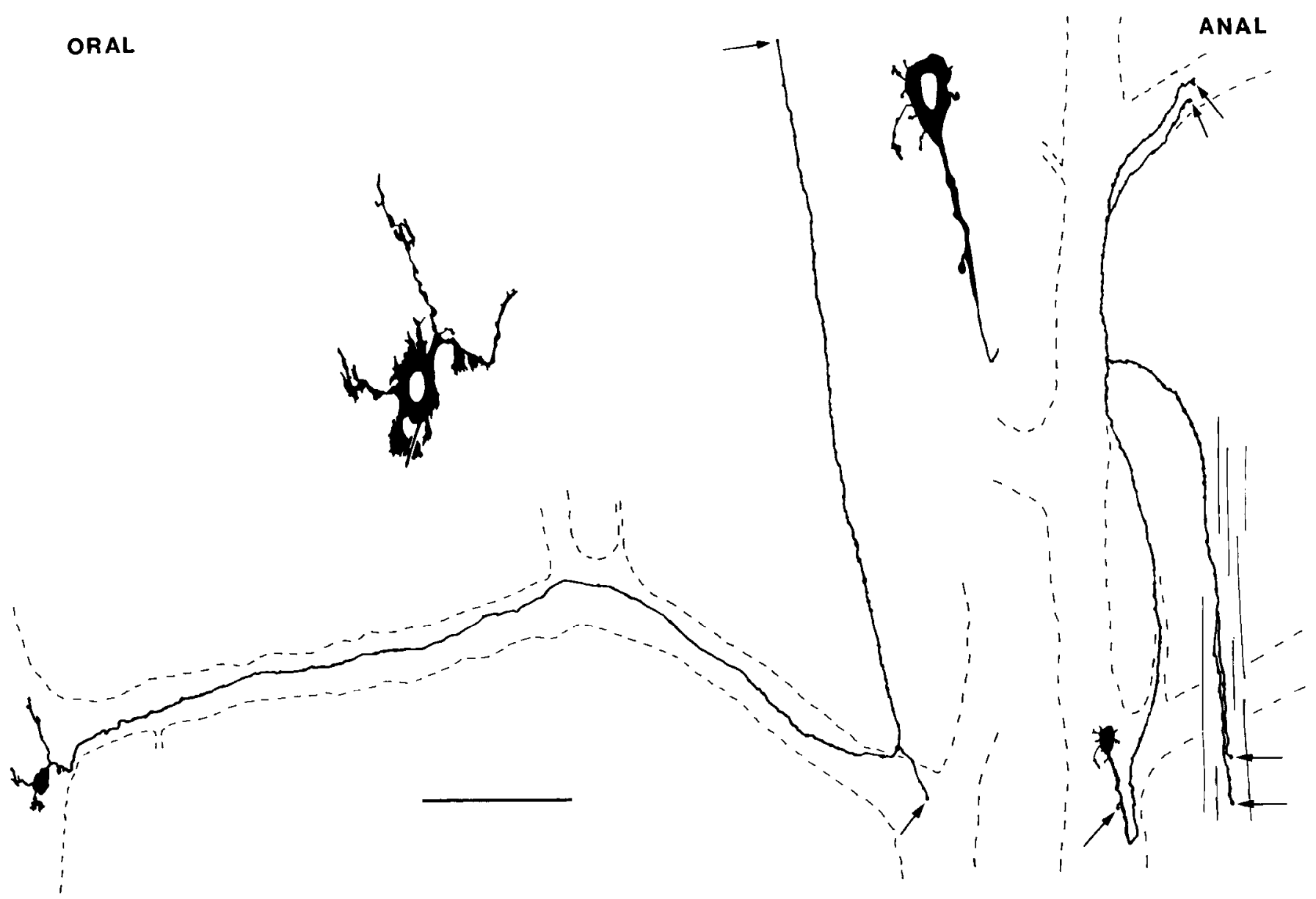

Figure 6. Camera lucida drawings showing the cell bodies and axonal projections of two S-neurons that appear to supply the circular muscle. Oral is to the left and anal is to the right. The branches of each axon end in expansion bulbs (arrows) that indicate sites at which the axons were broken when the circular muscle was removed during the dissection. Some of these branches actually enter superficial circular muscle, where they become varicose before ending in expansion bulbs. Other branches end in regions where no residual circular muscle had been left associated with the cleared myenteric plexus. Scale bar, $40 \mu \mathrm{m}, 100 \mu \mathrm{m}$.

neurons receiving input from descending, distension-activated, reflex pathways also received input from descending reflex pathways activated by deforming the mucosa (Fig. 4). Similarly, neurons receiving input from distension-activated ascending pathways were excited by ascending mucosal reflex pathways (Fig. 3). When a neuron received input from both ascending and descending distension reflex pathways, it usually received input from both ascending and descending mucosal reflex pathways (Fig. 7). Most neurons tested that responded to distension at a particular site also responded to mucosal stimulation at the same site. In contrast, only 2 of 42 neurons that failed to respond to distension responded to deforming the mucosa.

The decline in the responses to distension seen when the intestine was repeatedly distended did not affect the responses evoked in the same neuron by deforming the mucosa at the same site (Figs. 3, 4). Even when distension no longer evoked any response, deforming the mucosa at the same site evoked a powerful burst of fast EPSPs in many S-neurons. However, repeated mechanical stimulation of the mucosa led to a marked decline in the responses evoked by successive stimuli (Fig. 8).

\section{Convergence of reflex pathways running along the intestine.}

When the intestine was distended at two sites on the same side of an impaled S-neuron, it was found that if the nearer distension evoked a response, the more distant stimulus also evoked a burst of fast EPSPs (Fig. 9). This convergence between reflex pathways activated at different distances from the neuron bcing studied was seen in both the ascending and descending pathways. A similar convergence was seen in the reflex pathways excited by deforming the mucosa, where it was also noted that the decline in responses due to repeated stimulation at one site did not affect the responses evoked from a different stimulation site (Fig. 8).

\section{Table 2. Incidence of responses to mechanical stimulation of the mucosa in S-neurons whose responses to distension from oral or anal had been characterized}

\begin{tabular}{llcc} 
& Total & \multicolumn{2}{l}{$\begin{array}{l}\text { Response to } \\
\text { deforming the villi }\end{array}$} \\
\cline { 2 - 4 } $\begin{array}{l}\text { Response to } \\
\text { distension }\end{array}$ & Did respond & $\begin{array}{l}\text { Did not } \\
\text { respond }\end{array}$ \\
\hline Nonresponders & 42 & 2 & 40 \\
Desc & 15 & 13 & 2 \\
Asc & 15 & 13 & 2 \\
Both & 10 & 8 & 2 \\
\hline
\end{tabular}

For description of responses to distension, see Table 1. 
A. Oral distension

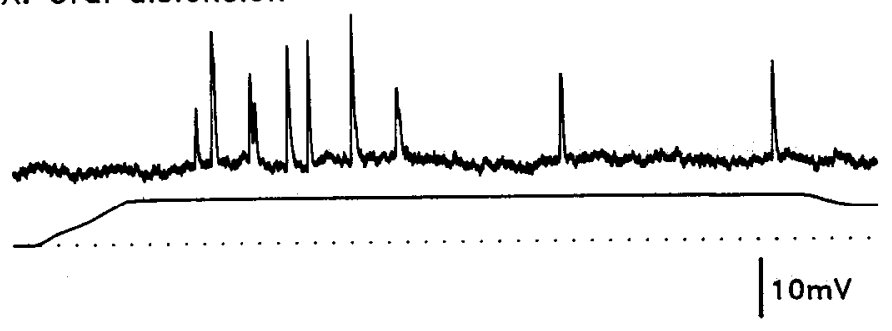

B. Anal distension
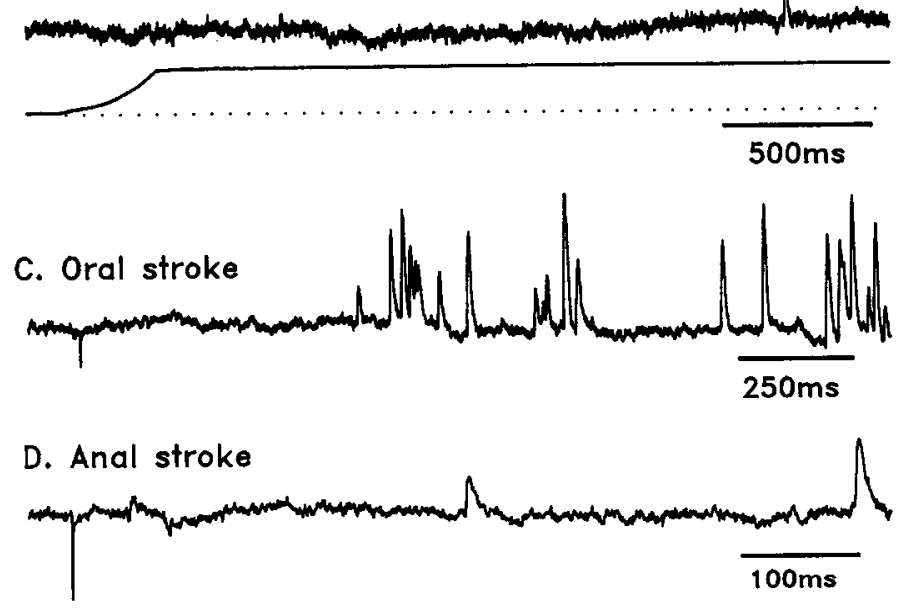

Figure 7. Convergence of ascending and descending reflex pathways evoked by distension and similar pathways excited by distortion of the mucosal villi onto a single S-neuron. $A$ shows the response evoked by distension $(0.3 \mathrm{ml})$ oral to the impaled neuron. $B$ shows the response evoked by distension $(0.5 \mathrm{ml})$ anal to the neuron. $C$ shows the response to distortion of the mucosa on the oral side, and $D$, the response to distortion of the mucosa on the anal side. Although the responses vary in magnitude, each stimulus evoked fast EPSPs.

\section{Discussion}

The present results provide the first description of the electrical behavior of neurons in the myenteric plexus during ascending excitation evoked by distension. They also extend the results of previous studies of myenteric neurons during reflexes evoked by deforming the mucosa (Bornstein et al., 1991) and during the descending inhibition evoked by distension (Hirst and McKirdy, 1974; Hirst et al., 1975).

The results obtained in the present study differ somewhat from those of the only previous investigation of the effects of distension on myenteric neurons (Hirst and McKirdy, 1974; Hirst et al., 1975). In the earlier study, it was reported that almost all S-neurons respond to distension of a segment of intestine oral to the point of recording with one or more fast EPSPs (Hirst et al., 1975). This contrasts with the present finding that only half of the S-neurons examined responded to distension and, for over a third of the neurons that did respond, an input only from ascending pathways was detected. In the present study, the latencies of the first fast EPSPs in the descending responses evoked by distension ranged from $0.30 \mathrm{sec}$ to $1.06 \mathrm{sec}$ and all the responses were transient. In contrast, Hirst et al. (1975) reported two different descending responses to distension: a shortlatency transient response similar to that seen in the present study and a long-latency $(3-11 \mathrm{sec})$ maintained response that
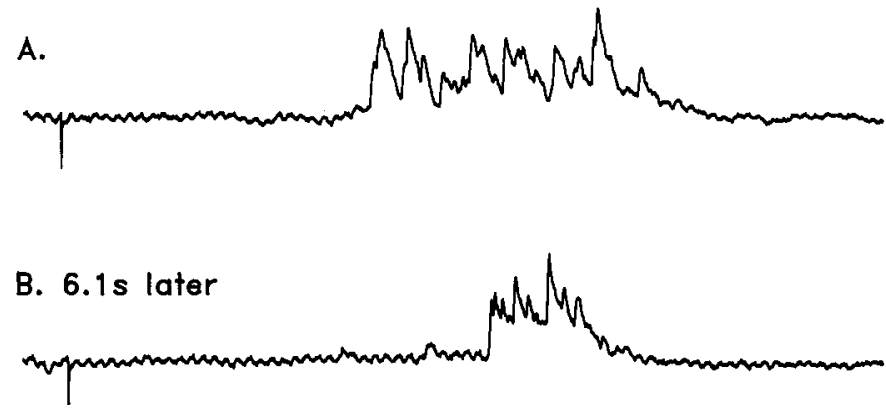

C. $5.5 \mathrm{~s}$ later

$10 \mathrm{mV}$

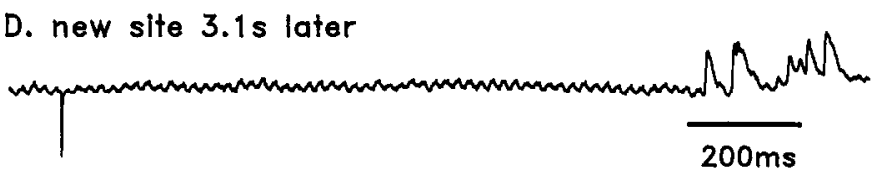

Figure 8. Convergence of responses to mucosal distortion applied at two different sites anal to the impaled S-neuron. The stimuli in $A-C$ were all applied at the same site and were separated by $6.1 \sec (A-B)$ and $5.5 \mathrm{sec}(B-C)$. The stimulus in $D$ was applied $5 \mathrm{~mm}$ farther from the recording site $3.1 \mathrm{sec}$ after the stimulus in $C$. In each trace, the downward deflection shows the point at which the brush touched the mucosal surface. The responses to successive stimuli applied at the same site declined markedly, but a similar stimulus at a different site was still capable of evoking significant numbers of fast EPSPs.

was seen in a separate population of S-neurons. The lower proportion of responding neurons in the present study appears to reflect the absence of the long-latency sustained response; Hirst et al. (1975) estimated that this response was seen in about half the S-neurons they studied.

These differences may reflect differences in the way the distending stimulus was applied. In the present study, the intestinal wall was distended by inflating a balloon underneath the serosal surface of an opened segment of small intestine; this stimulus probably did not distort the mucosal villi. Hirst et al. (1975) distended the intestine by inflation of a balloon placed in the lumen of an intact segment of small intestine, a stimulus that would simultaneously stretch the intestinal wall and deform the mucosal villi around the full circumference. Mucosal stimulation enhances the reflex responses evoked in the circular muscle by distension (Smith et al., 1991; Yuan et al., 1991); thus, the luminal balloon may provide a more effective stimulus or even activate additional descending pathways.

\section{Functional identities of responding neurons}

All the neurons studied in these experiments lay at least $1.5 \mathrm{~cm}$ from the distending balloons used to excite the reflex pathways. Those neurons that responded to distension did so with a burst of fast EPSPs and thus were probably motor neurons and interneurons (see also Hirst et al., 1975; Bornstein et al., 1991). This conclusion is supported by the observation that all the neurons responding to distension were uniaxonal and most projected either to the longitudinal muscle (tertiary plexus neurons) 
or to the circular muscle. The other responding neurons projected along the intestine for considerable distances and probably included interneurons (Bornstein et al., 1991).

If the neurons that responded to distension were interneurons and motor neurons, then at least some of the neurons that did not respond might be sensory neurons too far from the stimuli to be excited by them. None of the AH/Dogiel type II neurons responded to distension or, indeed, mechanical stimulation of the mucosa (see also Bornstein et al., 1991). This is consistent with the hypothesis [discussed in detail elsewhere (Pompolo et al., 1989; Furness et al., 1990; Bornstein et al., 1992)] that the AH/Dogiel type II neurons are sensory neurons. The morphology of the AH/Dogiel type II neurons indicates that their sensory processes project less than $1 \mathrm{~mm}$ orally or anally from their cell bodies (Bornstein et al., 1992).

\section{Convergence of the reflex pathways}

The results indicate that most, if not all, motor neurons to either the circular or the longitudinal muscle are common to both the distension-activated pathways and to the mucosa-to-muscle reflex pathways. Although few neurons that could be identified structurally as interneurons were examined in this study, it seems likely that interneurons distant from the site of stimulation are also common to both pathways.

The observation that the great majority of longitudinal muscle motor neurons receive input from both ascending and descending reflex pathways has important implications for the role of the longitudinal muscle in the intestine. Most longitudinal muscle motor neurons are likely to be excitatory (Hirst et al., 1975; Brookes et al., 1991). Thus, it would be expected that either distension or mechanical stimulation of the mucosa would produce excitation at both oral and anal sites in the longitudinal muscle. This might account for the preliminary shortening of the longitudinal muscle that appears to be characteristic of peristaltic reflexes examined with the Trendelenburg technique (Kosterlitz and Robinson, 1957).

The ascending and descending reflex pathways also converged on four neurons that did not appear to supply the longitudinal muscle; three of these appeared to be motor neurons supplying the circular muscle. This is consistent with recordings made from the circular muscle in previous studies of the reflexes evoked by distension or mechanical stimulation of the mucosa (Hirst et al., 1975; Smith and Furness, 1988; Smith et al., 1990). These studies reported that distension could evoke excitatory junction potentials anal to the point of stimulation (Hirst et al., 1975) and that either stimulus could evoke inhibitory junction potentials oral to the point of stimulation (Smith and Furness, 1988; Smith et al., 1990). Thus, while the major components of the reflexes are an ascending excitation and a descending inhibition, there is also evidence for descending excitatory and ascending inhibitory pathways. It is possible that such pathways may play an important role in the mixing behavior seen between propulsive activity in vivo (Cannon, 1902).

Considerable evidence suggests that separate sensory neurons mediate the mucosa-to-muscle and distension reflexes. Although removal of the mucosa prevents activation of the mucosa-to-muscle reflexes (Smith and Furness, 1988; Yuan et al., 1991), the distension reflexes persist (Smith et al., 1990). The decline in the reflexes evoked by successive distensions seen in the present study and in previous studies of the reflexes recorded in the circular muscle (Smith et al., 1990, 1991) does not cause a concomitant decline in the response to mechanical stimulation

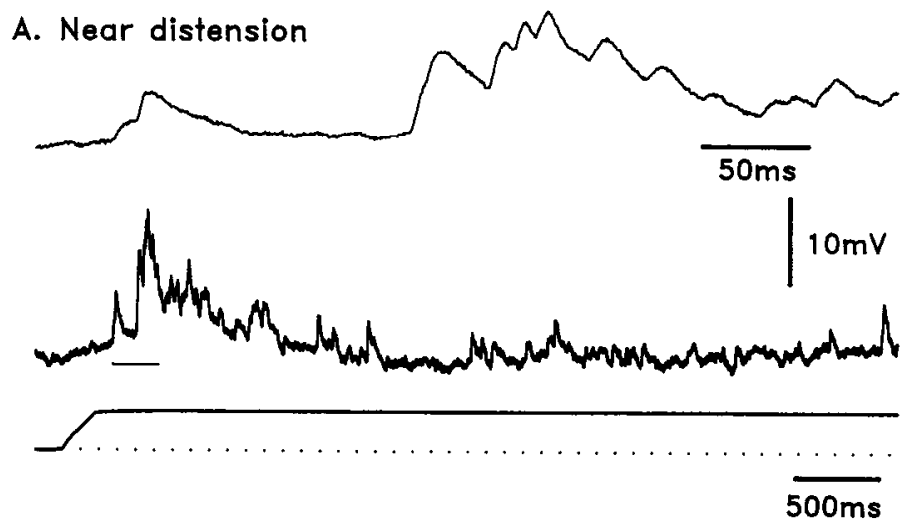

B. Far distension

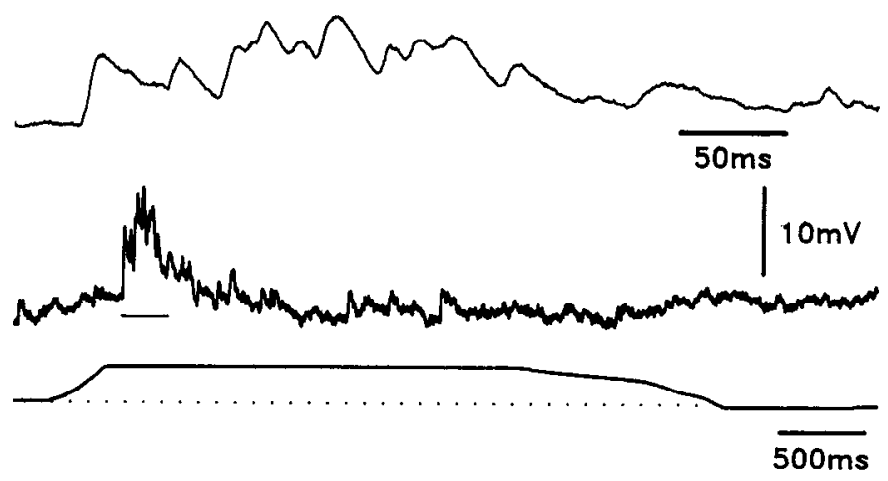

Figure 9. Convergence of responses to distension applied at two different sites oral to the impaled S-neuron. $A$ shows the response to inflation of the nearer balloon $(0.35 \mathrm{ml}) . B$ shows the response to inflation of a balloon $(0.4 \mathrm{ml})$ lying $15 \mathrm{~mm}$ more oral than that used in $A$. Note that a loose fold of intestine was left between the two balloons so that there was no mechanical interaction between the two stimuli; this meant that the length of intestine separating the two stimulus sites was approximately $20 \mathrm{~mm}$. The upper trace in each section of the figure shows a part of the response (indicated by the line below the middle trace) on an expanded time scale. Each stimulus evoked fast EPSPs in this S-neuron.

of the mucosa (Fig. 2 of Smith et al., 1991). These observations imply that the decline in the distension response must occur in parts of the reflex pathway that are proximal to the common interneurons and motor neurons. Further, mechanical stimulation of the mucosa can enhance the reflexes evoked by distension even when the mucosal stimulus is no longer effective in directly evoking a response in the circular muscle (Smith et al., 1991). This result also implies a functional separation between the two pathways at, or close to, the sensory neurons.

Pathways excited at different points along the intestine also converge onto these S-neurons (Figs. 8, 9). This suggests that the reflex pathways may involve chains of either ascending or descending interneurons that are common to each sensory modality. The neurons in these chains would receive input both from other interneurons in the chain and from local sensory neurons (probably AH/Dogiel type II neurons). They would have outputs to other interneurons in the chain and to motor neurons to the circular or longitudinal muscle.

\section{Circuits that mediate motility reflexes}

The results provide a clearer picture of the neuronal circuitry that mediates propulsive reflexes in the guinea pig small intes- 
tine. Although distinct ascending and descending pathways exist, these converge onto common motor neurons innervating the longitudinal muscle and onto some circular muscle motor neurons. The ascending and descending pathways can be activated by either distension or deformation of the mucosal villi, although these two stimuli appear to excite separate sensory neurons. However, it is possible that when both stimuli are applied together, as would happen under normal physiological conditions, another descending pathway is also activated. All of the microcircuits involved in the motility reflexes are repeated at spatially close intervals and with considerable overlap along the length of the intestine. Thus, the substantial convergence between both sensory modalities and between pathways projecting in opposite directions suggests that these microcircuits may also mediate more complex behaviors than the simple reflexes described here. These would include mixing movements, migrating complexes, and the behaviors during digestion when there is both mixing and propulsion of food.

\section{References}

Bayliss WM, Starling EH (1899) The movements and innervation of the small intestine. J Physiol (Lond) 24:100-143.

Bornstein JC, North RA, Costa M, Furness JB (1984) Excitatory synaptic potentials due to activation of neurons with short projections in the myenteric plexus. Neuroscience 11:723-731.

Bornstein JC, Furness JB, Smith TK, Trussell DC (1991) Synaptic responses evoked by mechanical stimulation of the mucosa in morphologically characterized myenteric neurons of the guinea pig ileum. J Neurosci 11:505-518.

Bornstein JC, Hendriks R, Furness JB, Trussell DC (1992) Ramifications of the axons of $\mathrm{AH}$-neurons injected with the intracellular marker biocytin in the myenteric plexus of the guinea pig small intestine. J Comp Neurol, in press.

Brookes SJH, Steele PA, Custa M (1991) Calretinin immunoreactivity in cholinergic motor neurones, interneurones and vasomotor neurones in the guinea-pig small intestine. Cell Tissue Res 263:471-481.

Cannon WB (1902) The movements of the intestines studied by means of the Rontgen rays. Am J Physiol 6:251-277.

Dogiel AS (1899) Ueber den Bau der Ganglien in den Geflechten des
Darmes und der Gallenblase des Menschen und der Säugetiere. Arch Anat Physiol (Leipzig) [Anat Abt Jg] 1899:130-158.

Erde SM, Sherman D, Gershon MD (1985) Morphology and serotonergic innervation of physiologically identified submucous neurons of guinea-pig's myenteric plexus. J Neurosci 5:617-633.

Furness JB, Costa M (1987) The enteric nervous system. Edinburgh: Churchill Livingston.

Furness JB, Trussell DC, Pompolo S, Bornstein JC, Smith TK (1990) Calbindin neurons of the guinea-pig small intestine: quantitative analysis of their numbers and projections. Cell Tissue Res 260:261-272.

Hirst GDS, McKirdy HC (1974) A nervous mechanism for descending inhibition in guinea-pig small intestine. J Physiol (Lond) 238:129143.

Hirst GDS, Holman ME, Spence I (1974) Two types of neurones in the myenteric plexus of duodenum in the guinea-pig. J Physiol (Lond) 236:303-326.

Hirst GDS, Holman ME, McKirdy HC (1975) Two descending nerve pathways activated by distension of guinea-pig small intestine. J Physiol (Lond) 244:113-127.

Johnson SM, Katayama Y, North RA (1980) Slow synaptic potentials in the neurones of the myenteric plexus. J Physiol (Lond) 301:505516.

Kosterlitz HW, Robinson JA (1957) Reflex contractions of the longitudinal muscle coal of the isolated guinea-pig ileum. J Physiol (Lond) 146:369-379.

Pompolo S, Furness JB, Bornstein JC, Hendriks R, Trussell DC (1989) Dogiel type II neurons in the guinea-pig small intestine: ultrastructure in relation to other characteristics. In: Nerves in the gastrointestinal tract (Singer MV, Goebell H, eds), pp 57-67. Carnforth, UK: Martin Lister.

Smith TK, Furness JB (1988) Reflex changes in circular muscle activity elicited by stroking the mucosa: an electrophysiological analysis in the isolated guinea-pig. J Auton Nerv Syst 25:205-218.

Smith TK, Bornstein JC, Furness JB (1990) Distension-evoked ascending and descending reflexes in the circular muscle of guinea-pig ileum: an intracellular study. J Auton Nerv Syst 29:203-213.

Smith TK, Bornstein JC, Furness JB (1991) Interactions between reflexes evoked by distension and mucosal stimulation: electrophysiological studies of guinea-pig ileum. J Auton Nerv Syst 34:69-76.

Yuan SY, Furness JB, Bornstein JC, Smith TK (1991) Mucosal compression elicits polarized reflexes and enhances responses of the circular muscle to distension in the small intestine. J Auton Nerv Syst 35:219-226. 